\title{
DISCUTINDO SEXUALIDADE NA FORMAÇÃO DE PROFESSORES
}

Ademir Henrique Manfré, Camila Medeiros de Araújo, Daniele C. Nogueira Gonçalo.

Universidade do Oeste Paulista - UNOESTE, Faculdade de Ciências, Letras e Educação, Presidente Prudente,SP. E-mail: camilascaioni@outlook.com

\section{RESUMO}

Este artigo é decorrente de uma pesquisa empírica inserida no eixo temático da sexualidade infantil na escola. Apresenta a importância da abordagem desse tema no curso de formação de professores juntamente com a concepção e postura do professor diante da problemática abordada em sala de aula. Realizamos a aplicação de questionários estruturados contendo dez (10) questões abertas voltadas para a formação, considerações e atitudes dos professores acerca do tema sexualidade na escola e que lecionam no primeiro ciclo do ensino fundamental em escolas públicas municipais na região de Presidente Prudente. Apresentaremos, neste artigo, os resultados da análise das quatros questões que julgamos serem as mais relevantes. Como resultado, compreendemos que a concepção de sexualidade do professor é fundamental para o esclarecimento de muitas questões que ainda permeiam como um tabu na escola. Portanto, sua formação é de fundamental importância para um debate significativo e esclarecedor no campo educacional.

Palavras-Chave: Educação. Formação de professores. Sexualidade. Escola.

\section{DISCUSSING SEXUALITY IN TEACHERS ' FORMATION}

\begin{abstract}
This article is due to empirical research inserted into the thematic axis of sexuality, which is focused on child sexuality in the school. It proposes to present the importance of the approach of this theme in the course of teachers ' training together with the conception and posture of the teacher in the face of the problematic discussed in the classroom. We conducted the application of structured questionnaires containing ten (10) open issues focused on training, considerations and attitudes of teachers who teach in the first cycle of elementary school in municipal public schools in the region of prudent president. In this article, we shall present the results of our investigation, only the analysis of the four issues that we deem to be the most relevant. As a result we understand the teacher's conception of sexuality is crucial for the clarification of many issues that still have a taboo in school. Therefore, its formation is of fundamental importance for a meaningful and enlightening debate on this thematic in the school.
\end{abstract}

Keywords: Education. Training of teachers. Sexuality. School. 


\section{INTRODUÇÃO}

Há tempos, a sexualidade é considerada como um tema polêmico seguido de vários tabus, pois a sociedade buscou, no decorrer de sua constituição, definir uma moralidade sexual comumente aceitável, definindo um único significado para a sexualidade. Atualmente, vivenciamos um grande impasse, já não é possível "controlar" o surgimento das diversidades sexuais e suas manifestações (Louro, 2000, p. 53). Diante do exposto, este artigo apresenta as observações de nossa pesquisa realizada por meio de levantamento de dados, acerca da concepção docente em relação à sexualidade infantil. O resultado dessa investigação evidencia que o professor necessita de uma formação constante acerca da problemática da sexualidade no ambiente escolar.

\section{OBJETIVOS}

A pesquisa teve por objetivo geral investigar e apresentar a temática da sexualidade infantil na escola. Essa investigação sustentou-se no referencial teórico de alguns autores do campo psicanalítico e dos estudos culturais sobre gênero, sexualidade e corpo. Por meio de uma investigação empírica, analisamos o modo como os professores dos anos iniciais do ensino fundamental - ciclo I - entendem a sexualidade infantil na escola.

\section{METODOLOGIA}

Optou-se por uma pesquisa de base empírica, com análise de dados (análise de conteúdo de Bardin), os quais foram coletados em sete escolas públicas municipais de ensino fundamental ciclo I - da região de Presidente Prudente/SP

Algumas coletas de dados foram realizadas em reuniões de HTPC e outras individualmente nas dependências escolares. Tivemos um total de quarenta e cinco participações. Para a realização da pesquisa, utilizamos um questionário estruturado no qual, primeiramente, coletamos informações a respeito da formação do professor, tempo de magistério, idade e em qual ano do ensino fundamental leciona. Em seguida, dez questões foram elaboradas sobre a temática proposta. Neste artigo, apresentaremos apenas quatro questões, as quais julgamos ter maior relevância para 0 estudo proposto.

Dentre os caminhos metodológicos elencados para este estudo, utilizamos o método de análise de conteúdos de Bardin, em que a partir das respostas apresentadas pelos professores, utilizamos palavras-chave e agrupamos em categorias as resposta que tinham proximidade de sentido e significado.

A pesquisa está cadastrada junto ao SGP/UNOESTE, com o protocolo de número 2768, aprovada pelo Comitê de Ética em Pesquisa (CEP). Mantivemos os nomes das escolas e dos professores em sigilo.

\section{RESULTADOS E DISCUSSÃO}

Apresentaremos, neste momento, a interpretação e análise de quatro questões (do total de 10) que constituem nosso questionário da pesquisa por considerarmos as mais importantes. Questões analisadas:

1) O que significa sexualidade para você?;

2) Em sua formação, houve alguma disciplina específica que tratasse do tema sexualidade na escola? Comente;

3) Em sua opinião, com que idade se deve:

a) Começar a namorar, b) Ter a primeira relação sexual? Por quê?;

4) Como você acha que esses problemas poderiam ser resolvidos?"

Em relação à primeira questão, apreendemos duas categorias interpretativas:

- Visão BIOLÓGICA da sexualidade; 
- Discussão de GÊNERO.

Categorizamos como "biológica" as respostas em que as palavras-chave remetiam ao corpo como sendo "natural, desenvolvimento, relação sexual e afetuosa, intimidade entre casal, as diferenças entre os órgãos genitais masculinos e femininos". Observamos que, quando a palavra sexualidade é pronunciada ou vista no ambiente escolar, é automaticamente direcionada ao corpo humano tal como ele é e sua finalidade de reprodução em sua maioria. Referente a uma visão evolutiva naturalista. Násio (1999, p. 48), em seu livro O prazer de ler Freud, retoma que "Do ponto de vista da psicanálise, a sexualidade humana não se reduz ao contato dos órgãos genitais de dois indivíduos, nem à estimulação de sensações genitais".

Em relação à primeira questão ( $O$ que significa sexualidade para você ?), evidenciaram-se as seguintes respostas dentro da categoria "biológica": Questionário A) "algo natural que faz parte do desenvolvimento dos seres humanos". Questionário B) "sexualidade é um desejo natural que faz parte do desenvolvimento do ser humano". Questionário C) "é quando a criança começa a descobrir que seu corpo está em transformação e que seus sentimentos se tornam curiosos em relação homem/mulher e o sexo mesmo". Estas respostas apontam para questões do corpo do ser humano, de seu desenvolvimento.

Ainda na primeira questão, mas dentro da categoria discussão de gênero, evidenciaram-se as seguintes respostas: Questionário A) "O que diferencia homem mulher". Questionário B) "conhecimento do corpo". Questionário C) "É tudo o que envolve questões de comportamento gênero de causa pessoal". Mesmo que se evidencie o "corpo", o gênero é independente da questão biológica (do sexo que determina feminino/masculino) e sim uma construção social e comportamental do sujeito quanto a identidade não fixa sua sexualidade (BUTLER apud LOURO, 1997, p.28).

A Terceira questão " Em sua formação, houve alguma disciplina específica que tratasse do tema sexualidade na escola? Comente", temos as categorias:

- Ausência de formação;

- Disciplina específica (psicologia);

- Temas transversais;

- Negado devido a tabu.

Com relação à primeira categoria - ausência de formação - , fica claro para nós que, de fato, a sexualidade é raramente tratada na formação de professores. Ainda que tenha surgida a categoria disciplina especifica (psicologia), esperava-se então que a sexualidade fosse tratada em sua amplitude. Porém, não é isso que constatamos com os dados coletados, pois a sexualidade vem sendo tratada apenas na perspectiva biológica como evidencia a primeira questão. Essas construções mostram a inexistência de uma abordagem específica da temática em um trabalho pedagógico específico como a discussão da sexualidade na escola. Os temas transversais remetem a uma questão curricular, pois trata-se de um dos seis temas apresentados no Parâmetro Curricular Nacional (PCN).

A terceira questão "Em sua opinião, com que idade se deve: a) Começar a namorar, b) Ter a primeira relação sexual? Por quê?". Para a primeira alternativa foram mencionadas idades entre 12 e 18 anos. Destoando apenas uma menção de 25 anos. Alguns pesquisados não responderam.

Faz-se necessário, mais uma vez, diferenciarmos a sexualidade genital de sexualidade. A primeira refere-se ao próprio corpo, aos órgãos genitais e ao aparelho reprodutor. Seu prazer está vinculado e é alcançado com o coito. Enquanto a segunda, constitui-se a partir da primeira infância, é a vivência do prazer independente da realização do sexo, está além dos limites do corpo.

Percebemos que as idades apontadas nas respostas acima coincidem com o início da puberdade, cronologicamente falando, o que nos remete ao amadurecimento e finalização do 
desenvolvimento dos órgãos genitais no sentido biologizante. Em Psicanálise, esse é o momento em que a pulsão volta a se direcionar ao sexual e o sujeito passa a se interessar e buscar o outro sujeito como objeto de satisfação.

Quanto à segunda alternativa: B) ter a primeira relação sexual, temos duas categorias que ao mesmo tempo representa uma visão limitada da sexualidade. Os pesquisados apontaram:

- Após o casamento;

- Conscientização do ato;

- Não informado;

- Pós-puberdade.

Como conscientização, amparados pelas respostas dadas pelos/as professores (as), percebemos a presença de um discurso em que o sujeito precisa ser esclarecido acerca das implicações da relação sexual: adquirir uma doença sexualmente transmissível - DST ou até mesmo transmiti-la, ter uma gravidez indesejada ou não planejada, daí a questão da conscientização. O que há de incluir as demais categorias (pós-puberdade e após o casamento). Mais uma vez, está diretamente relacionado com a questão biológica e saúde do corpo. É notória a necessidade do esclarecimento e conhecimento da amplitude da sexualidade para que os (as) professores (as) possam falar e considerar sobre a vivência dos prazeres em suas diferentes manifestações (gênero). Rosely Sayão (1997, p.111) aponta que a educação sexual realizada pela escola (quando ocorre) é baseada no aspecto informativo, biologizante e repressivo em relação às manifestações

Por fim, com a quarta questão "Como você acha que esses problemas poderiam ser resolvidos?", observamos que as categorias elencadas nesta questão já foram apontadas em outras questões. Entendemos então, que esta resume as demais discussões. As categorias são

- Currículo;

- Formação continuada;

- Relação família e escola.

A categoria "Currículo" foi mencionada com mais frequência seguida da família. Essa maior menção do currículo nos faz pensar na necessidade de se ter inserida a temática da sexualidade. Apontou ser um dos pontos que direcionam a abordagem e a discussão na escola. Sendo um dos principais documentos norteadores da prática pedagógica e de conteúdos. É a partir do currículo e Britzmam (apud LOURO 2015), sugere que o currículo esteja próximo à dinâmica da sexualidade e ao cuidado em si. O qual exige da predisposição do professor em estudar a postura de sua escola e de como ela interfere na discussão da sexualidade. Logo, a pensar em propostas de como possibilitar discussões que de fato atendam a curiosidade de seus alunos, explorando a extensão e surpreendentes sintomas de sua própria ansiedade (p.108.109).

\section{CONSIDERAÇÕES}

Ao concluir a pesquisa, evidenciamos e confirmamos a hipótese de que a concepção de sexualidade do professor é fundamental para o esclarecimento de muitas questões que ainda permeiam como um tabu na escola. Portanto, sua formação é de fundamental importância para um debate significativo e esclarecedor sobre essa temática na escola. Mesmo com os estudos psicanalíticos freudianos apresentando a existência de uma teoria da sexualidade infantil, ainda no campo educacional, a sexualidade é entendida resumidamente como algo biológico, um tabu, que faz parte do desenvolvimento humano, vista em disciplinas de ciências (evolução e reprodução sexual). Dito de outro modo, nossa investigação evidenciou que a sexualidade ainda é entendida apenas como amadurecimento biológico dos genitais, ou seja, evidencia-se uma importância apenas para o período pós-puberdade no estudo da sexualidade na escola. 
Essa visão reducionista evolucionista da sexualidade é sem dúvida oriunda da ausência da discussão e do conhecimento a respeito dela. É na formação inicial e continuada de professores, o momento propício de aprender e falar em sexualidade, sendo o seu conceito devidamente explorado em sua amplitude significativa. Conhecer e compreender as suas manifestações para poder lidar da melhor forma possível com as situações cotidianas escolares e sociais do aluno que incluam a temática, é um ponto que consideramos fundamental na formação de professores. Entendendo a própria justificativa de Freud (1905), que é na puberdade que ocorre a finalização da organização genital, mas que a sexualidade se manifesta e se desenvolve desde o nascimento.

Ainda que não tenhamos utilizado o currículo como objeto de estudo, pode-se dizer que o currículo destacou ser um dos pontos que direcionam a abordagem perante a questão da sexualidade na escola. Sendo um dos principais documentos norteadores da prática pedagógica e de conteúdos, vemos que essa temática não consta inserida nos cursos de formação logo também não está contida no planejamento, tampouco há projetos paralelos presentes na escola. A primeira questão (o que é sexualidade para você?), apontou uma dificuldade de definição e uma reduzida conceituação da sexualidade. Acreditamos que essa dificuldade é resultado do fato de os professores não conhecerem a temática e não conhecem por não terem estudado em sua formação inicial e ainda não serem instruídos a respeito na formação continuada.

Sabemos que nenhuma formação é efetivamente previsível, é impossível prever todas as situações que possam acontecer. Entretanto, é a formação docente que fundamentará e dará subsídios às intervenções pedagógicas. Freud (1905) complementa com a questão: qual o papel da educação na condenação da sexualidade? Refazemos essa questão: Por que na educação ocorre um processo de repressão e não de esclarecimento da sexualidade? Para que essa visão e prática da orientação sexual na educação ressignifique-se, torna-se necessário pensar em políticas públicas nos cursos de formação de professores, a fim de refletir sobre os tabus que permeiam essa discussão.

A pesquisa realizada ressalta a importante e relevante necessidade de se abordar a sexualidade infantil na formação docente, principalmente se considerarmos a diversidade que se manifesta socialmente.

\section{REFERÊNCIAS}

BRITZMAN, Deborah. Curiosidade, Sexualidade e Currículo. In: LOURO, Guacira Lopes (org.). O corpo educado: pedagogia da sexualidade. $2^{\circ}$ ed. Belo Horizonte: Autêntica, 2000.

BUTLER, Judith. 0 corpo Educado: pedagogias da sexualidade. $2^{\circ}$ ed. Belo Horizonte: Autêntica, 2000.

Corpos que pesam: sobre os limites discursivos do "sexo". In: Louro, Guacira Lopes. 0 corpo Educado: pedagogias da sexualidade. $2^{\circ} \mathrm{ed}$. Belo Horizonte: Autêntica, 2000, p. 151-172.

LOURO, Guacira Lopes. Gênero, sexualidade e Educação: uma perspectiva pós-estruturalista. $6^{\circ}$ ed. São Paulo: Vozes, 1997.

NASIO, J.D. O prazer de ler Freud. Rio de Janeiro: Jorge Zahar. Ed., 1999 